\title{
Best Paper of 2015 - International Union for the Study of Social Insects
}

(C) International Union for the Study of Social Insects (IUSSI) 2016

In 2011, the Union instituted an annual Award for the Best Paper published in Insectes Sociaux. This award carries with it an honorarium of $\$ 1000$.

Also this year, the members of the Editorial Board reviewed articles published in 2015 and nominated papers for this recognition. The winner of the 2015 Best Paper Award is:

Charbonneau D, Hillis N, Dornhaus A (2015) 'Lazy' in nature: ant colony time budgets show high 'inactivity' in the field as well as in the lab. Insect. Soc. 62:31-35

Congratulations to the authors! 